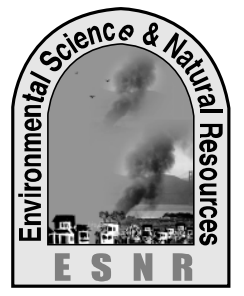

J. Environ. Sci. \& Natural Resources, 5(2): 295 - 300, 2012

ISSN 1999-7361

\title{
Estimation of the Fecundity of Jat Puti, Puntius sophore (Hamilton)
}

\author{
K. Bithy ${ }^{1}$, M. I. Miah ${ }^{1}$, M. S. Haque ${ }^{1}$, K. R. Hasan ${ }^{2}$ and M. F. Islam ${ }^{1}$ \\ ${ }^{1}$ Department of Fisheries Management, Bangladesh Agricultural University, Mymensingh-2202 \\ ${ }^{2} \mathrm{Ph} . \mathrm{D}$. Fellow, Dept. of Fisheries Management, Bangladesh Agricultural University, Mymensingh-2202
}

\begin{abstract}
The fecundity of 100 gravid female fishes of Jat puti, Puntius sophore, was collected from the experimental ponds of the Field Laboratory Complex, Faculty of Fisheries, Bangladesh Agricultural University (BAU), Mymensingh was estimated during the period from June to August 2011. Collected samples were clustered month-wise: group A (collected in June), group B (collected in July) and group C (collected in August). The estimated fecundity ranged of 7951 to 17670; 8135 to 23053 and 12461 to 15105 eggs and the mean gonadosomatic index (GSI) of $23.44 \pm 2.50 ; 30.47 \pm 4.52$ and $28.43 \pm 2.99$ was estimated for the fish group of $\mathrm{A}, \mathrm{B}$, and $\mathrm{C}$, respectively. The relationship between fecundity and total length was linear and it was expressed as: $\mathrm{Ln} \mathrm{F}=1634 \mathrm{ln}$ TL-1972; Ln F= 119405 ln TL-273.53 and Ln F= 1831.6 ln TL+ 825.31 in group A, B, and C, respectively. The regression equation between body weight and total length was linear and it was expressed as: Ln W= 2.2128 ln TL- 0.7048; Ln W=2.0207 ln $\mathrm{TL}+0.3493$ and $\mathrm{Ln} \mathrm{W}=1.4438 \ln \mathrm{TL}+5.5694$, in group A, B, and C, respectively. The regression equation between body weight and fecundity was linear and it was expressed as: $\mathrm{F}=656.84 \mathrm{~W}+199.96, \mathrm{~F}=438.16 \mathrm{~W}+2470, \mathrm{~F}=1116.1 \mathrm{~W}-3433.5$, in group $\mathrm{A}, \mathrm{B}$, and $\mathrm{C}$, respectively. The fecundity was highly correlated with the total length, and body weight and $P$. sophore may be a medium fecund fish.
\end{abstract}

Keywords: Fecundity, Jat puti, Puntius sophore

\section{Introduction}

Fecundity of the fish is the most important aspects of the reproductive biology of the fish which must be understood to explain the variation in the level of production as well as to make efforts to increase the amount of harvest. Alternatively fecundity may be expressed per unit body weight of post stripes fish when it is known as relative fecundity because the number of eggs produced for each unit increase in weight shows significant linear variation. Fecundity may be expressed in terms of the number of eggs produced per brood fish in a breeding season (Lagler, 1956). It is sometime referred to as total or absolute fecundity or more usually just as fecundity (Heese, 1990). The number of ripe eggs or mature eggs produced by a brood fish having every short single spawning season is readily ascertained at full maturity by artificially stripping the eggs from the fish, this number is known as fecundity. It is important to know the number of eggs, fry and young that could be produced from individual brood fish for purpose of fisheries management and aquaculture industry. In Bangladesh 54 freshwater fish species are in threats of different levels of extinction including 32 small indigenous fish species (IUCN, 2003) and among them $P$. sophore is recognized as threaten condition. For sustainable aquaculture, we should give special emphasis on our indigenous fish species that deserve to be brought under culture and management that will meet our annual fish intake as well as protect our indigenous fish species from extinction. To evaluate the commercial potentialities of a fish stock, information on the fecundity of the fish composing the stock is essential. Knowledge of a reproductive biology of fish is essential for evaluating the life history culture practices and the management of the fishery (Doha and Hye, 1970).

\section{Materials and Methods}

\section{Collection of brood fish}

A total of 100 gravid females of $P$. sophore were collected from the ponds of the Fisheries Field Laboratory Complex, Faculty of Fisheries, Bangladesh Agricultural University, Mymensingh, during the months of June, July, and August, 2011. At least 31 fishes were collected in each month. The breeder's body structure was easily identified on the basis of external feature of their abdomen, vent and pectoral fins. After selection of the fishes, the specimens were preserved in $10 \%$ buffered formalin. The fishes were kept into three labeled vials according to the month.

\section{Measure of length and weight}

The standard length and total length were recorded separately to the nearest centimeter scale respectively. A steel scale was used to measure the length of the body. The weight of the specimens was taken by an electric balance and the weights were recorded to the nearest gram. The ovary of the individual fish was taken out carefully and preserved in $10 \%$ buffered formalin. 


\section{Calculation of gonadosomatic index (GSI)}

The GSI is the percentage of gonad weight to the total weight of the fish. The GSI of the collected fish was calculated for each of the female separately and using by the following formula:

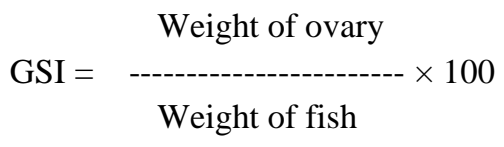

\section{Fecundity estimation}

Fecundity has been considered as the number of ripening eggs in the female prior to spawning (Bagenal and Braum, 1978). Gravimetric method or weight method (Lagler, 1956) was used for estimation of the fecundity of $P$. Sophore. Gravimetric method seemed to offer the best possibility of minimizing error due to its simple and easy sampling techniques. The Gravimetric method has used for its greater efficacy over the other methods. The Gravimetric or weight method has been successfully used by Doha and Hye (1970), Shafi et al. (1978), Dewan and Doha (1979), Mustafa et al. (1983).The gravimetric method was done by the following way, before estimation of the fecundity of the fish species under study, ovaries were cut into some sections or pieces from where pieces removed from the front, mid and rear-section of each ovary and weighed $(0.22 \mathrm{gm})$.

This value was proportional to the total ovary weight; the number of eggs $\left(\mathrm{F}_{1}\right)$ for the sub-sample was estimated by using the following equation:

$$
\begin{aligned}
\text { Fecundity }\left(F_{1}\right)= & \text { No. of eggs in sub sample } \times \text { Gonad weight } \\
\hdashline \text { Weight of sub sample } & \text { (Yelden and Avsar, 2000). }
\end{aligned}
$$

Later, by taking the mean number of three sub-sample fecundities $\left(\mathrm{F}_{1,2} \mathrm{~F}_{2}\right.$ and $\left.\mathrm{F}_{3}\right)$, the individual fecundity for each female fish was calculated by the following equation:

Fecundity $\left(\mathrm{F}_{\mathrm{e}}\right)=\quad \begin{gathered}\mathrm{F}_{1}+\mathrm{F}_{2}+\mathrm{F}_{3} \\ ---------\end{gathered}$

In this way fecundity of 100 fish were obtained.

\section{Data analysis}

From the above data, the relationship of different parameters such as total length and body weight, total length and fecundity, body weight and fecundity were determined as simple linear relationship with the help of MS Excel Programme. Coefficient of correlation (r), regression equation, standard deviation, was also determined.

\section{Results and Discussion}

\section{Gonadosomatic index}

The values of GSI of $P$. sophore were varied from 17.53-52.14 (Table 1). The average GSI values were recorded $23.44 \pm 2.50,30.47 \pm 4.52$ and $28.43 \pm 2.99$ in June, July and August respectively. The highest GSI of $P$. sophore was 52.14 obtained in the month of July (group B). The variation in gonadosomatic index of $P$. sophore might be associated with the degree of maturity of ova and spawning. This finding agrees with the finding of Das (1998) for N. notopterus (pallas). Afroze and Hossain (1990) for A. mola and Ramanondo sarker (2005) for Pseudeutropius atherinoides.

\section{Fecundity of P. sophore}

Fecundity was estimated with a range of 7951 to 23053 eggs for a corresponding standard length and body weight of the fish $5.5 \mathrm{~cm}, 10.12 \mathrm{gm}$ and $10 \mathrm{~cm}$, $26.5 \mathrm{gm}$ respectively, which was comparatively lower than Puntius sarana, its fecundity ranged from 18925 to 78929 eggs and length between $155 \mathrm{~mm}$ and 250 mm (Mustafa et al., 1983). Bhuiyan, et al. (1987) estimated the fecundity of Puntius gonionotus and mean fecundity was obtained as 14321 eggs with a range of 2254.67 to 6964.73 from fishes having a mean total length and mean body weight of $200.13 \pm 20.58 \mathrm{~mm}$ and $196 \pm 34.379 \mathrm{~g}$ respectively. Variation of fecundity among the population may result largely from selectivity different environmental factors (Temperature, Sunlight, weather etc.), of which temperature is considered the most probable selective factor (Jonsson and Jonsson, 1999). This could be due to the availability of food in the natural and captive condition. The variation in fish fecundity is due not only fish length and weight but also due to fish nutritional diet, running water and influence of vitamins.

Relation between total length and body weight, total length and fecundity, body weight and fecundity In this experiment the fecundity bears a linear relationship between total length and body weight, total length and fecundity, body weight and fecundity. For test of this hypothesis in $P$. sophore, the regression equation and coefficient of correlation of these variables were determined. To determine the above parameters the total length (TL), body weight (W), were taken as independent variables (X), while fecundity (F) as depends on them was taken as dependent variable $(\mathrm{Y})$. 
Table. 1. Mean $( \pm \mathrm{SD})$ of total length, standard length, body weight, ovary length, ovary weight, GSI and fecundity of $P$ sophore of group A, B and C

\begin{tabular}{|l|l|l|l|l|l|l|l|}
\hline $\begin{array}{l}\text { Group } \\
\text { name }\end{array}$ & $\begin{array}{l}\text { Total } \\
\text { Length }(\mathrm{cm})\end{array}$ & $\begin{array}{l}\text { Standard } \\
\text { Length }(\mathrm{cm})\end{array}$ & $\begin{array}{l}\text { Body } \\
\text { Weight }(\mathrm{g})\end{array}$ & $\begin{array}{l}\text { Ovary } \\
\text { length }(\mathrm{cm})\end{array}$ & $\begin{array}{l}\text { Ovary } \\
\text { weight }(\mathrm{g})\end{array}$ & GSI & Fecundity \\
\hline A & $9.43 \pm 1.72$ & $\begin{array}{l}7.93 \pm 1.47 \\
5.5-10.5\end{array}$ & $\begin{array}{l}20.15 \pm 4.57 \\
10.12-30.41\end{array}$ & $\begin{array}{l}4.08 \pm 0.53 \\
3.00-4.90\end{array}$ & $\begin{array}{l}4.72 \pm 1.16 \\
2.79-6.20\end{array}$ & $\begin{array}{l}23.44 \pm 2.50 \\
17.53-27.97\end{array}$ & $\begin{array}{l}13438 \pm 3295 \\
\end{array}$ \\
\hline $7.00-12.00$ & & & & & & & \\
\hline B & $9.37 \pm 1.30$ & $7.97 \pm 1.25$ & $19.29 \pm 3.47$ & $4.45 \pm 0.60$ & $5.44 \pm 0.88$ & $30.47 \pm 4.52$ & $17114 \pm 1759$ \\
& $7.30-12.00$ & $6.00-10.00$ & $14.29-26.50$ & $3.50-5.50$ & $4.05-7.52$ & $21.86-52.14$ & $8135-23053$ \\
\hline C & $8.89 \pm 1.29$ & $7.11 \pm 0.99$ & $18.41 \pm 2.06$ & $4.42 \pm 0.48$ & $5.46 \pm 0.84$ & $28.43 \pm 2.99$ & $10921 \pm 2535$ \\
& $6.50-11.00$ & $5.00-9.00$ & $14.9-24.05$ & $3.50-5.40$ & $3.50-5.40$ & $25.00-35.68$ & $12461-15105$ \\
\hline
\end{tabular}

\section{Relation between total length and body weight}

The scatter plot obtained from the body weight and total length obtain the regression lines of each relationship. The total lengths (TL) of the fishes were plotted against their body weight (W) in logarithmic scale and show the regression to be positive as in the correlation for group A, B and C (Figs. 1, 2 and 3).

Ln $\mathrm{W}=2.2128$ ln TL- 0.7048 .

$\mathrm{Ln} \mathrm{W}=2.0207 \ln \mathrm{TL}+0.3493$.

$\mathrm{R}^{2}=0.696$ (group A)

$\mathrm{R}^{2}=0.5753$ (group B)

$\mathrm{Ln} \mathrm{W}=1.4438 \ln \mathrm{TL}+5.5694$

$\mathrm{R}^{2}=0.7652($ group $\mathrm{C})$

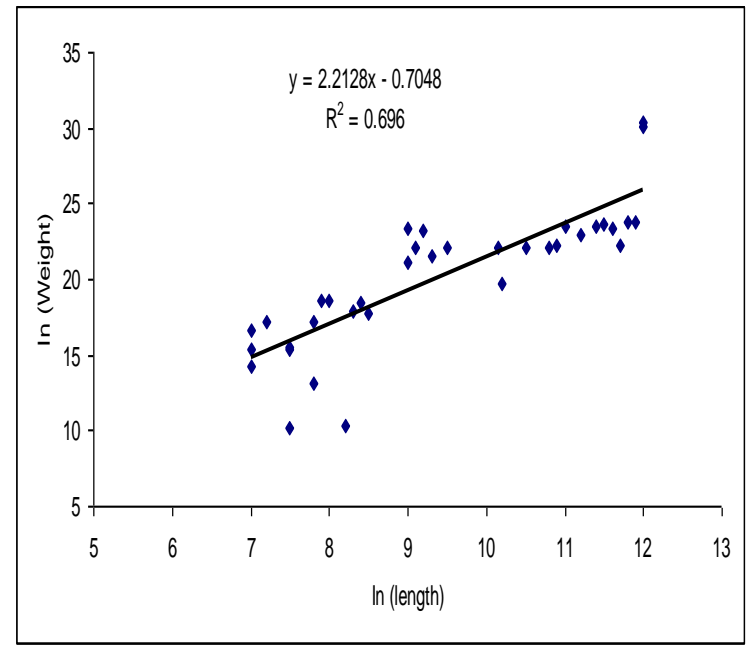

Fig. 1. Relationship between total length and body weight for group A
The correlation and co-efficient between total length and body weight were found 0.696, 0.5753, and 0.7652 for the group $\mathrm{A}, \mathrm{B}$ and $\mathrm{C}$ respectively, the total length of fish are significant at $95 \%$ level of significance. The total length increased significantly with the increase of the body weight. This type of relationship was reported by Parween et al. (2000) in Chanda nama (Hamilton) and Corica soborna. Ramanondo sarker (2005) in Pseudeutropius atherinoides. Environmental factors and food supply might affect the fecundity of fish (Bagenal, 1957). It is possible that the variation in fecundity of the $P$. sophore may be due to environmental conditions of the ponds.

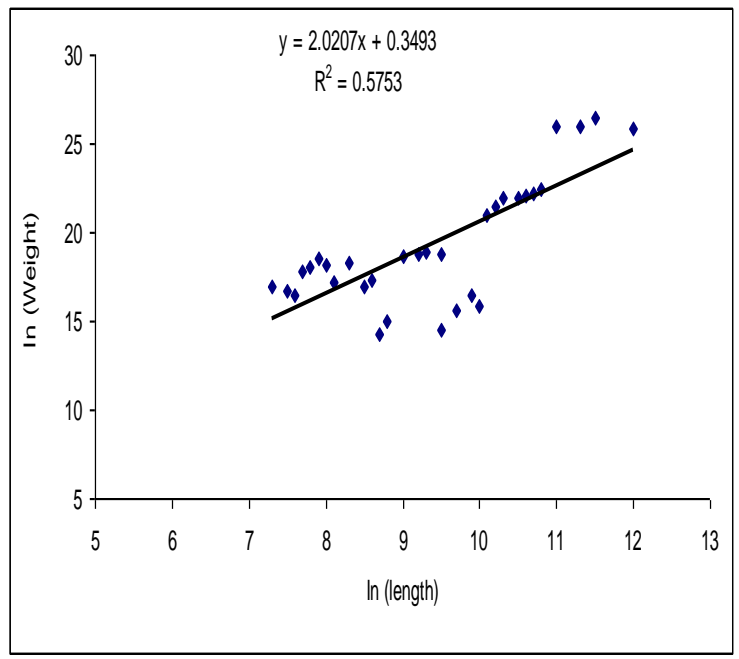

Fig. 2. Relationship between total length and body weight for group B 


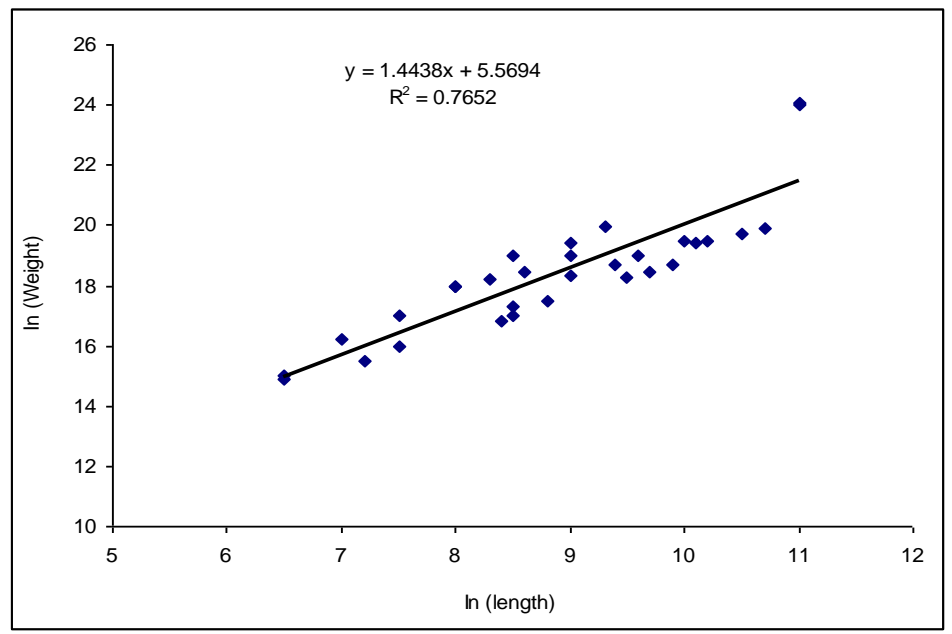

Fig. 3. Relationship between total length \& body weight for group C

\section{Relation between total length and fecundity}

In the determination of this relation, length was taken as independent variant, while fecundity as dependent variant (Figs. 4, 5 and 6). The relationship between the fecundity and total length was expressed as,
Ln $\quad \mathrm{F}=1634$ ln TL-
1972

Ln F= $119405 \ln \mathrm{TL}-273.53$

$\mathrm{R}^{2}=0.727$ (groupA)

$\mathrm{R}^{2}=0.7825$ (group B)

$\mathrm{Ln} \mathrm{F}=1831.6 \ln \mathrm{TL}+825.31$

$\mathrm{R}^{2}=0.8118$ (group C)

The correlation and co-efficient between total length

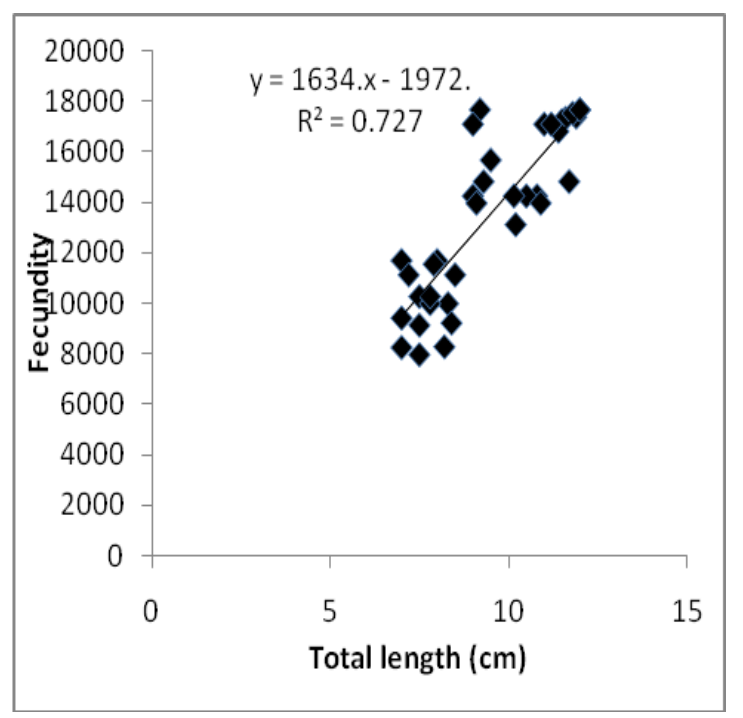

Fig. 4. Relationship between total length and fecundity for group A and fecundity were found 0.727 for the group A, 0.7825 group $\mathrm{B}, 0.8118$ group $\mathrm{C}$, the total length of fish are significant at $95 \%$ level of significance. The $r$ values are significant at $95 \%$ level of significance. The regression equations obtained by total length and fecundity of Puntius sophore of different and dependent on their total length. The fecundity increased significantly with increase of the total length. The similar results showed, Azadi et al. (1987) in Mystus vittatus (Bloch); Das (1998) in N. notopterus (pallas); Azadi and Mamun, (2004) in Amblypharyngodon mola (Hamilton).

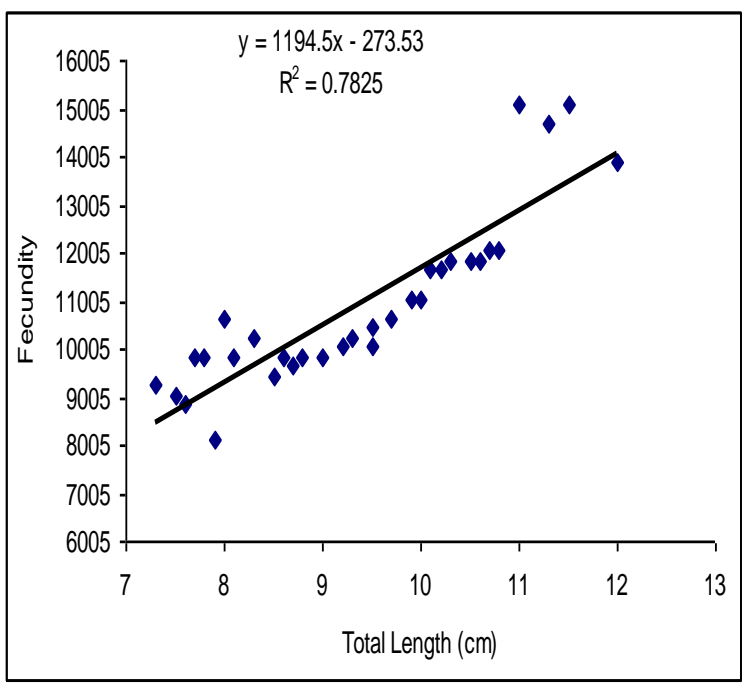

Fig. 5. Relationship between total length and fecundity for group B 


\section{Relation between body weight and fecundity}

The scatter diagram obtained from the fecundity and body weight showed a linear relationship (Figs.7, 8 and 9). In the determination of this relation, body weight was taken as independent variant while fecundity as dependent variant. The relationship between the fecundity and body weight was expressed as,

$\mathrm{F}=656.84 \quad \mathrm{~W}+199.96$.

$\mathrm{F}=438.16 \mathrm{~W}+2470$

$\mathrm{R}^{2}=0.8262$ (groupA)

$R^{2}=0.7472$ (group B)

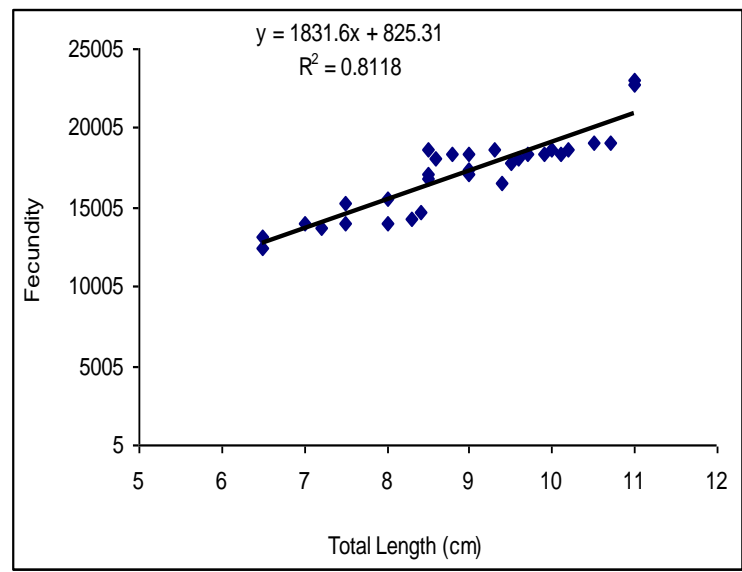

Fig. 6. Relationship between total length and fecundity for group $\mathrm{C}$

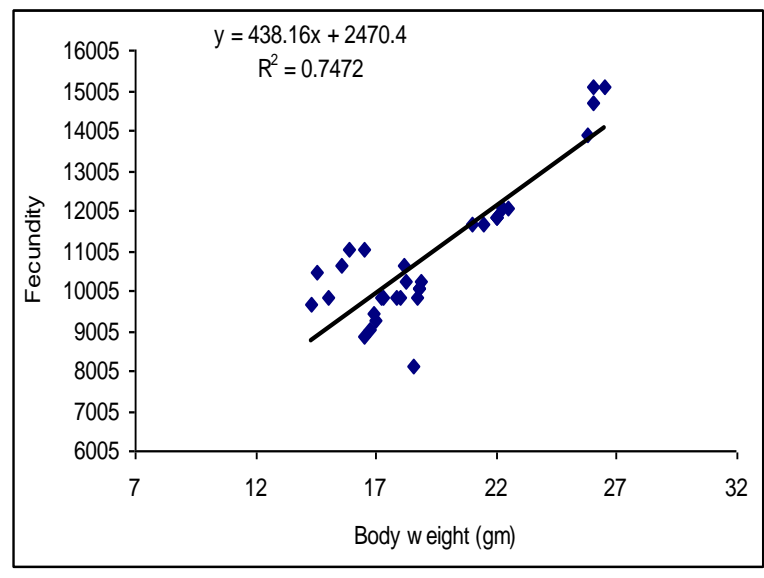

Fig. 8. Relationship between body weight and fecundity for group B weight
$\mathrm{F}=1116.1 \mathrm{~W}-3433.5$.

$\mathrm{R}^{2}=0.8212$ (group C)

The correlation and co-efficient between body weight and fecundity were found 0.8262 for the group A, 0.7472 group $\mathrm{B}, 0.8212$ group $\mathrm{C}$. The $\mathrm{r}$ values are significant at $95 \%$ level of significance.

The regression equation and scattered diagram showed a positive relation. Increase in fecundity with the increase in body weight is reported by, Bhuiyan, et al. (1987) in P. gonionotus. Azadi et al. (1987) in Mystus vittatus (Bloch). Parween (1984) in A. mola

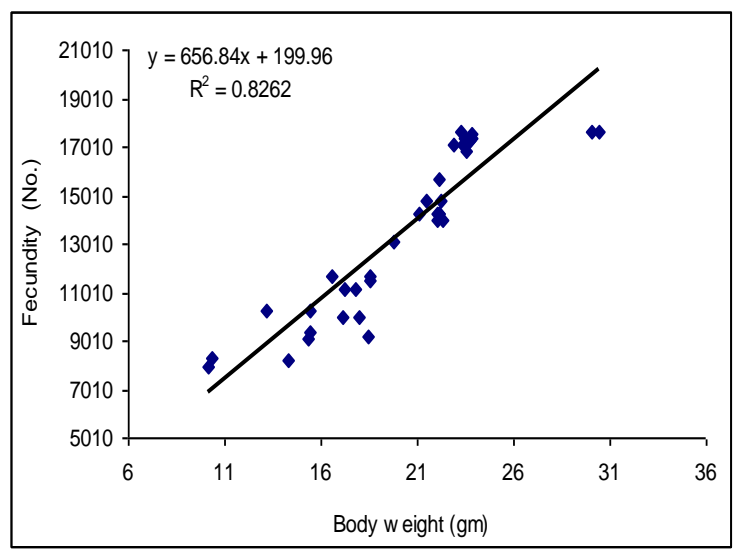

Fig. 7. Relationship between body \& fecundity for group A

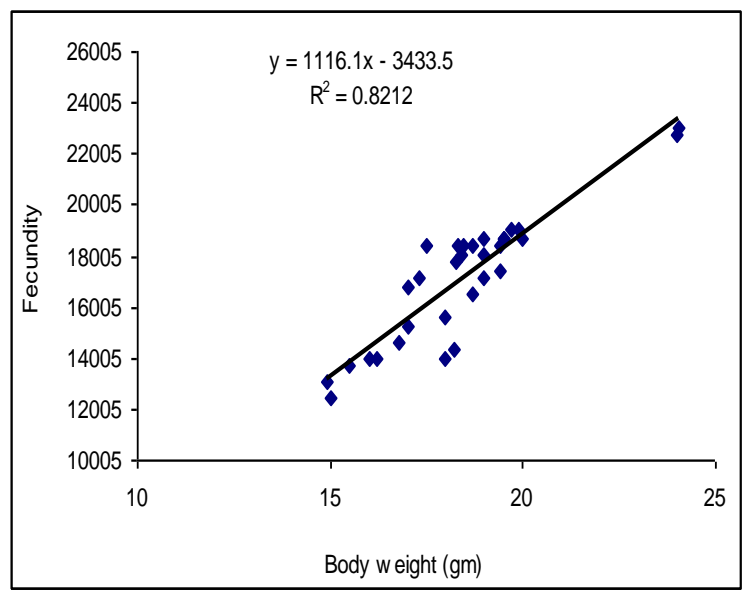

Fig.9. Relationship between body weight and fecundity for group C 


\section{Conclusion}

The present observations on fecundity reveal that $P$. sophore (7951 to 23053 eggs) is a fecund fish compared to other fishes like, Esomus danrica (392 to 2412 eggs), Amblypharyngodon mola (1021 to 13815 eggs), Ambassis nama (110 to 2448 eggs), Glossogobius giuris (376 to24668 eggs) and Colisa lalius (127 to 2309 eggs). Lower number of eggs might also be correlated with shorter development time rate of fingerling, which means higher survival rate. The higher number of eggs does not prove to be a disadvantage in reproductive potential. It is an indicator of population behavior and fecundity according to Panthulu (1961).

\section{References}

Afroze, S. and M. A. Hossain. 1990. The reproductive cycle of the freshwater fish Amblypharyngodon mola (Ham.) (Cypriniformes: Cyprinidae). Univ. J. zool. Rajshahi University., 9: 17-21.

Azadi, M. A. and A. Mamun. 2004. Reproductive biology of the Cyprinid, Amblypharyngodon mola (Hamilton) from the Kaptai Reservoir, Bangladesh. Pakistan J. of Biol. Sci., 7(10): 1727-1729.

Azadi, M. A.; M. A. Islam and S. R. Dev. 1987. Some aspects of the biology of Mystus vittatus (Bloch): Food and feeding habits and fecundity. Bangladesh Assoc. Adv. Sci., Dhaka (Bangladesh). The $12^{\text {th }}$ Annual Bangladesh Sci. Conf. Sec. 2, Dhaka, (Bangladesh). 36 pp.

Bagenal, T. B. and E. Braum, 1978. Eggs and Early Life History. IBP Hand Book No. 3, 3rd Edn. Blackwell Scientific Publication, Oxford, 106 pp.

Bagenal, T. B. and W. G. Cochran, 1957. Statistical Methods. 6th Edn., Oxford and IBH Publishing Co. Pvt. Ltd., New Delhi, India, Pages 593.

Bhuiyan, A, S. K. Islam. and T. Zaman. 1987. Fecundity of fresh water fish Puntius gonionotus (Bloch) (Cyprinidae: Cypriniformes) J. bio-sci., 3: 100-110.

Das, D. R. 1998. A study on the fecundity of Featherback, Notopterus notopterus (pallas) from two different sources (pond and Beel). M.Sc. Thesis, Department of Aquaculture, Bangladesh Agricultural University, Mymensingh.70 pp.
Dewan, S. and S. Doha. 1979. Spawning and fecundity of certain pond fishes. Bangladesh $J$. Agril., 4(1): 1-8.

Doha, S. and M. A. Hye. 1970. Fecundity of padma River hilsa, Hilsa ilisha (Ham.). Pakistan. J. Sci., 22 (3\&4): 176-184.

Heese, T. 1990. Gonad development and fecundity of white fish, Coregonus lalaretus (L.) from the Pomeranian Bay. Actalchthyological pascatoria (Poland). 20 (1): 3-12.

(IUCN) Bangladesh, 2003, Bangladesher Bipanno Prani. IUCN- The World Conservation Union, $294 \mathrm{pp}$.

Jonsson, N. and B. Jonsson, 1999. Trade-off between egg mass and egg number in brown trout. Journal of Fish Biology. 55: 767-783.

Mustafa, G.; Islam, K. R. Ali, S. and Alam, A. K. M. A. A. 1983. Some aspects of the biology of Puntius sarana (Ham.): Food and feeding habits in relation to fish size and fecundity. Bangladesh J. zool., 10 (2): 92-100.

Parween, S. 1984. Study on the culture methods and some aspects of biology of Amblypharyngodon mola. MS Thesis. Department of Zoology. Dhaka University. 137 pp.

Parween,S.; M. G. Mortuza, and M. A. Hossain. 2000. Some aspects of reproductive biology of two coarse fishes, Chanda nama (Hamilton) and Corica soborna (Hamilton- Buchanon) of Bangladesh. Pakistan J .Zool., 32 (2): 179-181.

Panthulu, V. R. 1961. Determination of age and growth of Mystus gulio by the use of pectoral spines with observations on its biology and fishery in Hoogly estuary. Proceedings of the National Institute of Science of India 27:198225.

Ramanondo, S. 2005. Studied on the fecundity of Pseudeutropius atherinoides, A thesis submitted to the Department of Aquaculture, for MS degree in Aquaculture, $68 \mathrm{pp}$.

Shafi, M. and M. A. Quddus. 1974. The Fecundity of the common punti, Puntius stigma (Cuvier \& Valenciennes) (Cyprinidae: Cypriniformes), Bangladesh J. Zool., Z (2): 133- 145.

Lagler, K. F. 1956. Freshwater Fishery Biology. Second Ed. W.M.C. Brown Company, Dubuque, lowa, $421 \mathrm{pp}$.

Yelden, K. and Avsar, S. R. 2000. Fecundities of some fresh water eel. Journal of zoology. 10: 60-67. 